$\begin{array}{cc}\text { ACADEMIA ROMÂNĂ } & \text { Rev. Roum. Chim., } \\ \text { Revue Roumaine de Chimie } & \text { 2019.64(12), 1063-1072 } \\ \text { http://web.icf.ro/rrch/ } & \text { DOI: 10.33224/rrch.2019.64.12.06 }\end{array}$

\title{
ELECTROCHEMICAL DETERMINATION OF NOREPINEPHRINE BY ADSORPTIVE STRIPPING VOLTAMMETRY USING A BARE BORON-DOPED DIAMOND ELECTRODE
}

\author{
Ertugrul KESKIN, ${ }^{a^{*}}$ Yavuz YARDIM, ${ }^{\mathrm{b}}$ Abdulkadir LEVENT $^{\mathrm{c}}$ and Zühre ŞENTÜRK ${ }^{\mathrm{d}}$ \\ ${ }^{a}$ Adiyaman University, Faculty of Pharmacy, Department of Analytical Chemistry, 02040 Adiyaman, Turkey \\ ${ }^{\text {b} Y u ̈ z u ̈ n c u ̈ ~ Y 1 l ~ U n i v e r s i t y ~ F a c u l t y ~ o f ~ P h a r m a c y, ~ D e p a r t m e n t ~ o f ~ A n a l y t i c a l ~ C h e m i s t r y ~} 65080$ Van, Turkey \\ ${ }^{c}$ Batman University, Faculty of Science, Department of Analytical Chemistry,72100, Batman, Turkey \\ ${ }^{\mathrm{d} Y u ̈ z u ̈ n c u ̈ ~ Y 1 l ~ U n i v e r s i t y ~ F a c u l t y ~ o f ~ S c i e n c e, ~ D e p a r t m e n t ~ o f ~ A n a l y t i c a l ~ C h e m i s t r y ~} 65080$ Van, Turkey
}

Received August 2, 2019

\begin{abstract}
A boron-doped diamond electrode was used for the first time for sensitive and selective analysis of norepinephrine (NE) using square wave voltammetry (SWV) technique. NE displayed one welldefined, irreversible and adsorption-controlled oxidation peak at about $+0.85 \mathrm{~V}$ (vs. $\mathrm{Ag} / \mathrm{AgCl}$ ) in Britton-Robinson buffer (BR, 0.1 M, $\mathrm{pH}$ 2.0) using cyclic voltammetry (CV) technique. The effect of supporting electrolyte, solution $\mathrm{pH}$ and instrumental variables on oxidation peak current were optimized. In optimal experiment conditions, it was found that there was an excellent correlation between oxidation peak current and NE concentration in the range of 1 to $100 \mu \mathrm{g} \mathrm{mL}^{-1}\left(4.9 \times 10^{-6} \mathrm{M}-4.9 \times 10^{-4} \mathrm{M}\right)$ with a detection limit of $0.254 \mu \mathrm{g} \mathrm{mL} L^{-1}\left(1.2 \times 10^{-6} \mathrm{M}\right)$ in $0.1 \mathrm{M} \mathrm{BR}$ buffer (pH 2.0) solution employing square-wave stripping mode. The developed technique can be used for the quantification of NE in the pharmaceutical formulation with acceptable recoveries.

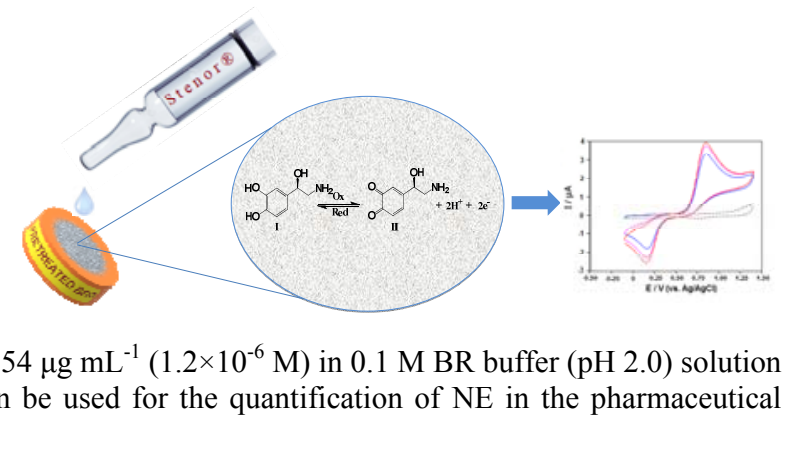

\section{INTRODUCTION}

Norepinephrine (NE), also known as noradrenaline, is one of the most important catecholamine class messengers with hormone and neurotransmitter roles in the central nervous system. ${ }^{1,2}$ The hormone NE is released directly from the adrenal medulla into the blood, while the neurotransmitter NE is secreted by the nerve endings. Many neurophysiological processes in the body relate to its multiple roles., When the organism is exposed to any physical or mental stress, it is released NE into the blood by the adrenal medulla to produce the fight-or-flight response. ${ }^{5}$ In response to this stressful condition, the body increases heart rate, triggers glucose release and increases skeletal muscle readiness. Therefore, NE is also called stress hormone. On the other hand, any inhibition of noradrenergic transmission is closely related to neurodegenerative disorders such as depression, stress, anxiety, attention deficit hyperactivity disorder. ${ }^{6,7}$ According to recent studies, the main cause of Parkinson's disease, which is one of the most common neurodegenerative disorder, is the insufficiency of NE source. ${ }^{8}$ Norepinenephrine is widely used as a medication for depression, attention deficit hyperactivity disorder and vasopressor states (hypotension patients). ${ }^{9}$ On the other hand, the use of $\mathrm{NE}$ in competitive games is prohibited by World Anti-Doping Agency (WADA) due to it increases sporting performance in athletes. ${ }^{10}$ Hence, it is crucial to develop a simple, rapid and sensitive analytical methodology for NE analysis from biological fluids

\footnotetext{
${ }^{*}$ Corresponding authors: e-mail: keskinertugrul@gmail.com; Tel: +90 416223 38 00; fax: +90 04162231774
} 
and pharmaceutical drugs due to its important role in human metabolism and clinical use in the treatment of various diseases.

Various analytical methods including liquid chromatography, ${ }^{11}$ gas chromatography, ${ }^{12}$ ion chromatography ${ }^{13}$ spectrophotometry ${ }^{14}$ electrophoresis ${ }^{2}$ and fluorescence spectroscopy ${ }^{15}$ have been employed for the determination of NE. Due to its being an electroactive molecule, interest in the electrochemical analysis of NE has increased in recent years. ${ }^{16}$ These analyses are mainly based on the modification of substrate materials such as carbon-based electrodes, gold, palladium and indium tin oxide (ITO) with polymer films or nanoparticles. ${ }^{17-26}$ Some of these modified electrodes have achieved high sensitivity and selectivity levels depending on the performance of the modifying chemical. ${ }^{17,22,27}$ However, the modification of these developed electrodes has disadvantages such as time, labor and the use of expensive chemicals. Electrochemical studies developed for $\mathrm{NE}$ analysis from different samples are presented in Table 2.

Boron-doped diamond (BDD) electrodes are a state-of-the-art electrode material that gains a new horizon to electrochemical analyses and enables the analysis of many electroactive species that can not be performed by traditional solid electrodes. The electrode material to be used in electrochemical analyses is expected to produce a stable electrode response, have a large potential window, enable to work in even the most aggressive environments, respond quickly, have low baseline current, and be economical. BDD is one of the outstanding electrode materials that fulfill all of these expectations. ${ }^{28}$ As a result of these properties, the BDD electrode has increased both the extent and quantity of electrochemical analyses. ${ }^{29}$

To the best of our knowledge, it was not found any study on the electrochemical behaviors and quantitative analysis of NE using unmodified BDD electrode. The objective of this work was to examine the electrochemical behavior of NE on unmodified BDD substrate and then was to establish fast, simple and environment-friendly voltammetric techniques for the quantification of NE by unmodified BDD in connection with SWV technique. The applicability of the developed technique was demonstrated by the analysis of commercial pharmaceutical. Furthermore, the obtained results are compared with those from a high-performance liquid chromatography (HPLC) method. The improved methodology can be an alternative for quantification NE in routine analytical applications with speed, simplicity, and precision.

\section{RESULTS AND DISCUSSION}

\section{Electrochemical behaviors of NE on bare BDD electrode}

$\mathrm{CV}$ is an important technique in terms of both elucidating the redox process of the related analyte and providing useful information in the evaluation of electron transfer kinetics. For this purpose, the electrochemical behavior of $50 \mu \mathrm{g} \mathrm{mL}^{-1}(243 \mu \mathrm{M})$ $\mathrm{NE}$ has been investigated on the anodically pretreated BDD electrode by $\mathrm{CV}$ in the $0.1 \mathrm{~mol} \mathrm{~L}^{-1}$ BR pH 2.0 buffer solution within the potential range from $-0.1 \mathrm{~V}$ to $1.4 \mathrm{~V}$ at scan rate of $100 \mathrm{mV} \mathrm{s}^{-1}$ repetitively (Fig.1). In addition, the $\mathrm{CV}$ of the solution containing only the supporting electrolyte (without NE) was recorded for comparison purposes (Fig. 1, dashed line)

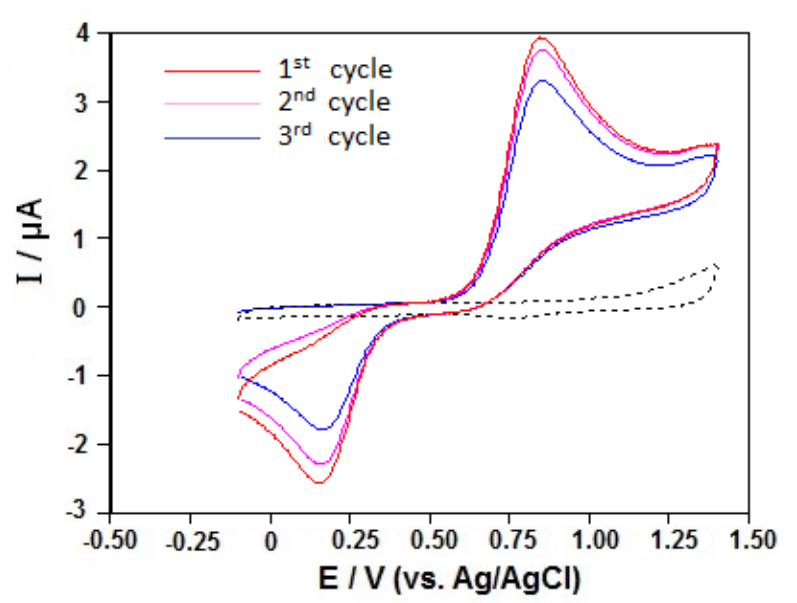

Fig. 1 - The repetetive CVs of $50 \mu \mathrm{g} \mathrm{mL}^{-1} \mathrm{NE}$ at the BDD electrode. Supporting electrolyte: $0.1 \mathrm{~mol} \mathrm{~L}^{-1} \mathrm{BR}(\mathrm{pH} \mathrm{2.0)}$. CV condition: $100 \mathrm{mV} \mathrm{s}^{-1}$; Dashed lines represent background current.

The cyclic voltammogram in BR buffer, $\mathrm{pH} 2.0$ showed an irreversible redox peaks. The first of these peaks is the oxidation peak at $+0.852 \mathrm{~V}$ which shows the transformation of NE (I) to the open-chain norepinephrine quinone (II) and the second peak which shows the reduction of this oxidized form back to NE form at $+0.174 \mathrm{~V}$ (Scheme 1) ${ }^{30}$ In other hand, decrease of redox peak currents on the $2^{\text {nd }}$ and $3^{\text {rd }}$ scans of consecutive CVs can be interpreted as passivation of the BDD electrode surface by product(s) of electrolysis.The electrochemical 
behaviour of NE well coincides with those previously reported in literature. ${ }^{18}$

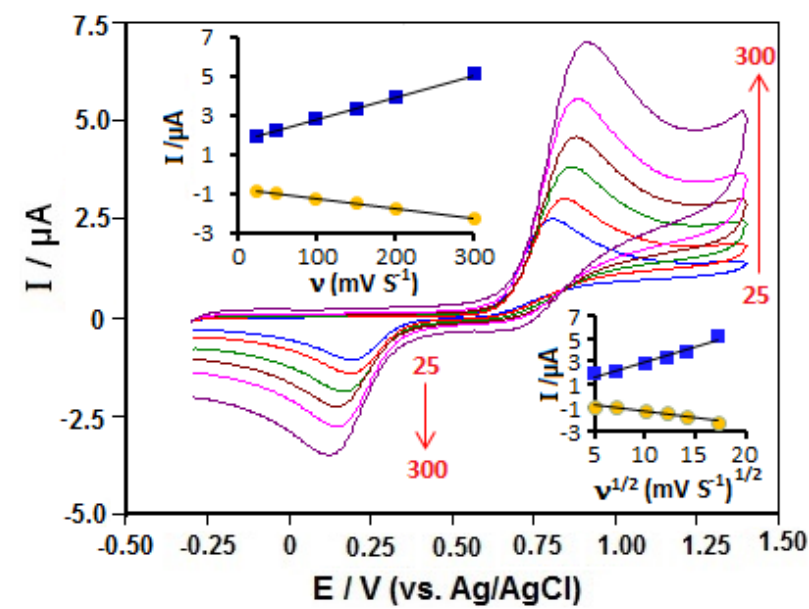

Fig. $2-\mathrm{CVs}$ of $50 \mu \mathrm{g} \mathrm{mL}^{-1} \mathrm{NE}$ in BR buffer solution ( $\mathrm{pH}$ 2.0) at BDD at electrode with from 25 to $300 \mathrm{mV} \mathrm{s}^{-1}$ and linear relationship $v$ and $v^{1 / 2}$ with $I$ in the insets.

In order to determine the nature of the electrode reaction, the influence of scanning rate on oxidation of $\mathrm{NE}$ at $\mathrm{BDD}$ electrode was also investigated by $\mathrm{CV}$ technique in BR buffer, $\mathrm{pH}$ 2.0. As shown in Figure 2, a linear relationship was found for $\mathrm{NE}$ with the scanning rate of both $\operatorname{anodic}\left(I p_{a}\right)$ and cathodic peak currents $\left(I p_{c}\right)$ in the range $25-300 \mathrm{mV} \mathrm{s}^{-1}$ according to Equation 1 and 2. However, when the same relationship was made against the square root of the scanning rate, linearity was impaired according to Equation 3 and 4. In addition, slopes of the equation $5(0.5218)$ and equation $6(0.5652)$ have confirmed that the electrode reaction is adsorption controlled. ${ }^{31}$ The corresponding regression equations are as follows:

$$
\begin{gathered}
I p_{a}=0.012 v+1.612(r=0.9994) \\
I p_{c}=-0.005 v-0.766(r=0.9989) \\
I p_{a}=0.255 \sqrt{v}+0.405(r=0.9844) \\
I p_{c}=-0.113 \sqrt{v}-0.231(r=0.9859)
\end{gathered}
$$

$\log I p_{a}=0.5218 \log v-0.5558(r=0.9960)$

$\log I p_{c}=-0.5652 \log v+0.9631(r=0.9945)(6)$

It is a known fact that peak potentials shift to more positive values with increasing scanning rate is a typical characteristic of irrversible electrode reactions. $^{21}$ The relationship between scan rate and shift in oxidation peak potential $\left(E p_{a}\right)$ of $\mathrm{NE}$ is given in equation 7 .

$$
E p_{a}(V)=0,075 \log v+0.7017(7)
$$

Laviron equation (Equation 8) is the most general expression of the relationship between the $\log v$ and $E_{p}{ }^{32}$

$$
E p(V)=E^{0}+(2,303 R T / \alpha n F) \log \left(R T k^{0} / \alpha n F\right)+2,303 R T / \alpha n F \log v
$$

where $\mathrm{E}^{0}$ is the formal potential, $\alpha$ is the electron transfer coefficient, $n$ is the electron transfer numbers, $k^{0}$ is the standard rate constant of the surface reaction and $v$ is the scan rate. Other symbols have their usual meanings. The linear relationship between $E p_{a}$ and $\log v$ was presented equation 7 , the value of $\alpha n$ was calculated quickly

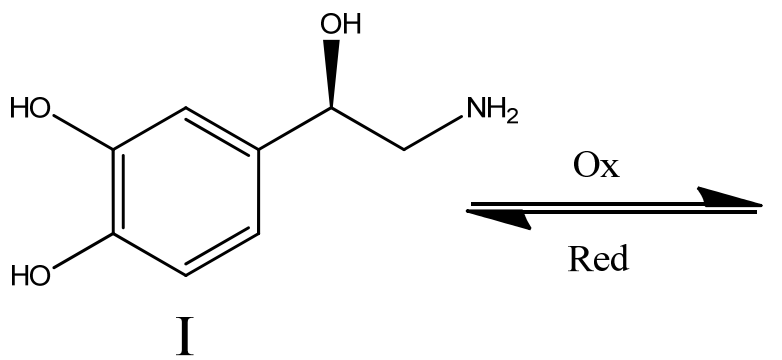

from the slope of the equation 7, and its $\alpha$ was 0.788 for $\mathrm{NE}$ oxidation. In general, $\alpha$ was approximated to be 0.5 in the response of quasi reversible electrode processes, so $n$ was obtained to be $1.6(\approx 2)$ for NE. In light of this information, the possible redox mechanism of $\mathrm{NE}$ can be expressed as follows:

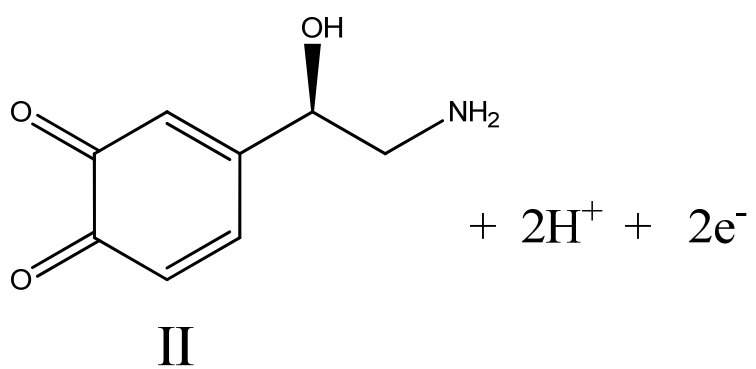

Scheme 1 - The redox mechanism of NE on OT-BDD electrode. 


\section{Effect of BDD pretreatment on the analytical signal}

The hydrogen- (cathodically pretreated, here referred as HT-BDD) or oxygen-terminated (anodically pretreated, here referred OT-BDD) BDD surface significantly affects the performance of this electrode against electroactive species.The BDD electrode is either OT-BDD or HT-BDD, depending on the type of electrochemical pretreatment step to be applied to the electrode surface $^{33}$. In the presence of an anodic current, the electrode surface predominantly converts to the OT-BDD form, while a cathodic current converts the electrode to the HT-BDD form. Figure 2 shows the measured SW voltammograms of NE oxidation after different pretreatment steps applied to the BDD surface. Obviously, the OT-BDD electrode appeared to exhibit higher activity in the oxidation of NE than the HT-BDD electrode. Due to its high performance, the anodic pretreatment step was applied to the BDD electrode at the beginning of each experiment day.

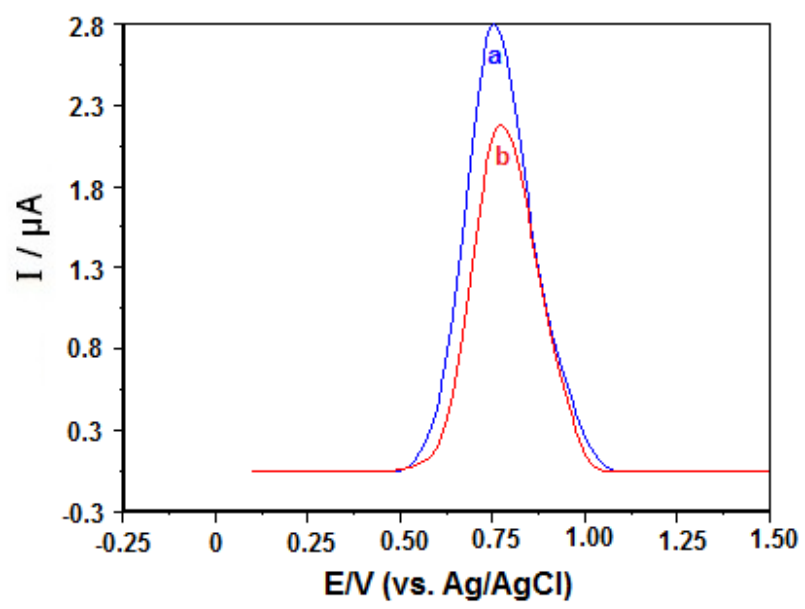

Fig. 3 - SWV curves obtained on an anodically (a) and a cathodically (b) pretreated BDD electrode, using $20 \mu \mathrm{g} \mathrm{mL}^{-1}$ NE. Supporting electrolyte: $0.1 \mathrm{~mol} \mathrm{~L}^{-1} \mathrm{BR}(\mathrm{pH} 2.0) \mathrm{SWV}$ conditions are same as Fig. 1.

\section{Influence of supporting electrolyte and pH}

The most suitable medium for the oxidation of NE was examined by SWV technique in various supporting electrolytes such as perchloric acid, acetate buffer solution (ABS), phosphate buffer solution (PBS) and Britton-Robinson (BR) buffer solutions ( $\mathrm{pH}$ 2.0-10.0). The oxidation peak morphology of NE in ABS and PBS medium was not good in both sensitivity and reproducibility. On the other hand, the best peak intensity was achieved in perchloric acid and BR buffer media (results not shown). However, since peaks in the perchloric acid medium were broad, BR buffer was chosen as the best medium for NE oxidation. Then, the effect of $\mathrm{pH}$ on oxidation peak current was examined in BR buffer in the range of 2-10. The best peak morphology and intensity were obtained in BR pH 2.0 medium (Fig. 4). In alkaline solution, although there was a relative increase in peak intensities, the peak splittings occurred in these regions. In particular, the splitting around $\mathrm{pH} 10$ significantly affected not only the peak shape but also its intensity. These results confirm the information that the morphology OT-BDD electrode surface is changed due to degradiation especially in alkaline solution above $\mathrm{BR} \mathrm{pH} 9.0^{34}$. In addition, the effect of $\mathrm{pH}$ changes on peak potentials was investigated. As shown in Figure 4, it shifts to slightly less positive values in neutral and basic solutions, but these shifts in peak potentials $(E p)$ are irregular. As can be seen in Fig. 4, between $\mathrm{pH} 3.0$ and 5.0 the plot of $E p$ versus the solution $\mathrm{pH}$ value gave straight line $(E p(\mathrm{mV})=$ $=-50.5 \mathrm{pH}+956.7, r=0.999)$, indicating that the oxidation of $\mathrm{NE}$ at the OT-BDD electrode is a $\mathrm{pH}-$ dependent reaction. The results show that the maximum peak currents of the compound obtained at strongly asidic solution, thus, $\mathrm{pH} 2.0$ was chosen in the following experiments.

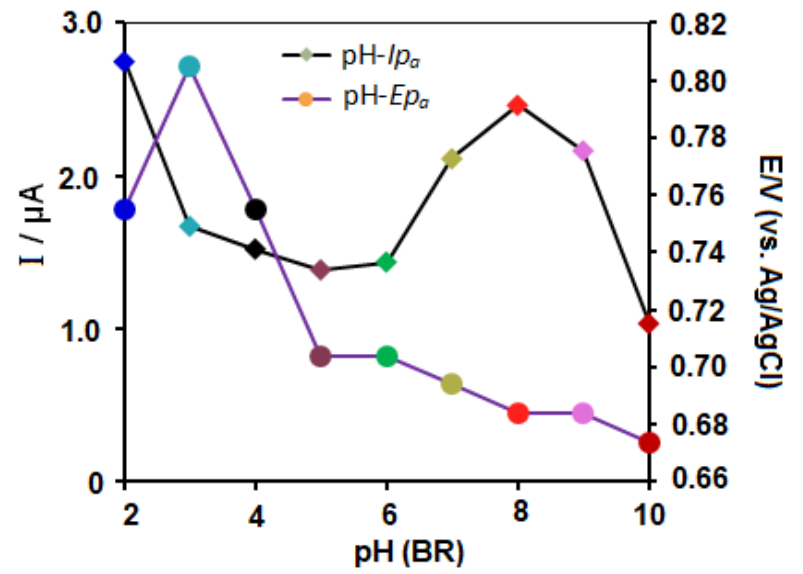

Fig. 4 - Dependence of $I p_{a}$ and $E p_{a}$ versus pH (BR pH 2.010.0) in $20 \mu \mathrm{g} \mathrm{mL}^{-1} \mathrm{NE}$ solution at the OT-BDD electrode with accumulation time $120 \mathrm{~s}$, at open circuit accumulation potential. SWV conditions were $25 \mathrm{~Hz}$ frequency, $10 \mathrm{mV}$ scan increment, and $40 \mathrm{mV}$ pulse amplitude.

\section{Optimization of accumulation variables and device parameters}

In order to perform the quantitative analysis of NE with the highest sensitivity, the effects of 
device variables and accumulation variables on the peak current were examinated. This effect was examined by changing one parameter while keeping the others constant for $10 \mu \mathrm{g} \mathrm{mL}^{-1}(4.9 \mathrm{x}$ $\left.10^{-5} \mathrm{M}\right) \mathrm{NE}$ solution in $0.1 \mathrm{~mol} \mathrm{~L}^{-1} \mathrm{BR}$ solution (results not presented). In the case of adsorption phenomena, the optimization of accumulation variables such as accumulation time $\left(t_{a c c}\right)$ and accumulation potential $\left(E_{a c c}\right)$ significantly affect the current responses of the electroactive compounds. In this case, the effects of accumulation variables on peak current signals were investigated by SWV in a stirred solution $(500 \mathrm{rpm})$. For this purpose, firstly $t_{a c c}$ was examined in the range of $0-420 \mathrm{~s}$ at open circuit $E_{a c c}$. The intensity of NE oxidation peak increased gradually as the $t_{a c c}$ increased up-to $60 \mathrm{~s}$. With time longer than $60 \mathrm{~s}$, the peak currents were almost unchanged which indicates that the surface area of electrode is saturated with NE molecules. On the other hand, the dependence of the stripping peak currents on $E_{a c c}$ was evaluated either in potential range from +0.1 to $+1.0 \mathrm{~V}$ or at open-circuit $E_{a c c}$ while the $t_{a c c}$ was $60 \mathrm{~s}$. The maximum peak currents were achieved at the potential of opencircuit $E_{a c c}$. Therefore, $60 \mathrm{~s}$ was selected as optimum $t_{a c c}$ and open-circuit accumulation as optimum $E_{a c c}$ for NE oxidation.
In addition, the effect of pulse parameters such as frequency, scan increment, and amplitude on the oxidation peak of $\mathrm{NE}$ was investigated by the SWV method and optimum conditions were determined for each variable in the studied range. Table 1 shows the optimal conditions for both instrumental and other variables.

\section{Analytical application}

After optimization of working conditions (chemical conditions and instrumental parameters), the analytical performance was evaluated by examining the oxidation peak current as a function of concentrations of NE (Fig.5). Construction of the analytical curve was obtained for NE on the OT-BDD electrode. In this context, known amounts of NE stock solution were added sequentially to the voltammetric cell and the current responses obtained from square-wave adsorptive stripping voltammetry (SW-AdSV) for each addition were evaluated. The SW-AdSV voltammograms were recorded by additions of NE over 1 to $100 \mu \mathrm{g} \mathrm{mL}^{-1}\left(4.9 \times 10^{-6} \mathrm{M}-4.9 \times 10^{-4} \mathrm{M}\right)$ concentration range and the respective analytical curve was shown in Fig. 5, inset. A highly linear calibration graph was obtained by plotting oxidation peak currents against NE concentrations in the specified range expressed by equation 9 :

$$
\operatorname{Ip}(\mu A)=0.2176 C+0.0873(r=0.999, n=17)
$$

In the equation, $I_{p}$ represents the oxidation peak current, $C$ NE concentration, $r$ correlation coefficient and $\mathrm{n}$ the number of experiments, respectively.

The detection limit (LOD) and quantification limit (LOQ) values were calculated using $3 \mathrm{~s} / \mathrm{m}$ and $10 \mathrm{~s} / \mathrm{m}$ formulas respectively. The values of $s$ and $m$ in the formula indicate the standard deviation of 10 consecutive measurements at the lowest concentration in the calibration curve and the slope of the related calibration curve, respectively. By using these formulas, LOD and LOQ values were found to be $0.254 \mu \mathrm{g} \mathrm{mL} \mathrm{m}^{-1}\left(1.2 \times 10^{-6} \mathrm{M}\right)$ and $0.847 \mu \mathrm{g} \mathrm{mL}^{-1}\left(3.96 \times 10^{-6} \mathrm{M}\right)$, respectively.

Table 1

Optimized the analytical parameters for NE

\begin{tabular}{lll}
\hline Parameters & Studied Range & Optimum Condition \\
\hline $\mathrm{pH}$ & BR pH 2.0- BR pH 10.0 & BR pH 2.0 \\
Electrode pretreatment methods & Anodic or cathodic & Anodic \\
Accumulation potential & $0.1-1.0 \mathrm{~V}$ or Open circuit & Open circuit \\
Accumulation time & $0-420 \mathrm{~s}$ & $60 \mathrm{~s}$ \\
Device variables (for SWV) & & \\
a) Frequency & $25-100$ & $50 \mathrm{~Hz}$ \\
b) Scan increment & $6-20$ & $12 \mathrm{mV}$ \\
c) Pulse amplitude & $30-100$ & $70 \mathrm{mV}$ \\
\hline
\end{tabular}



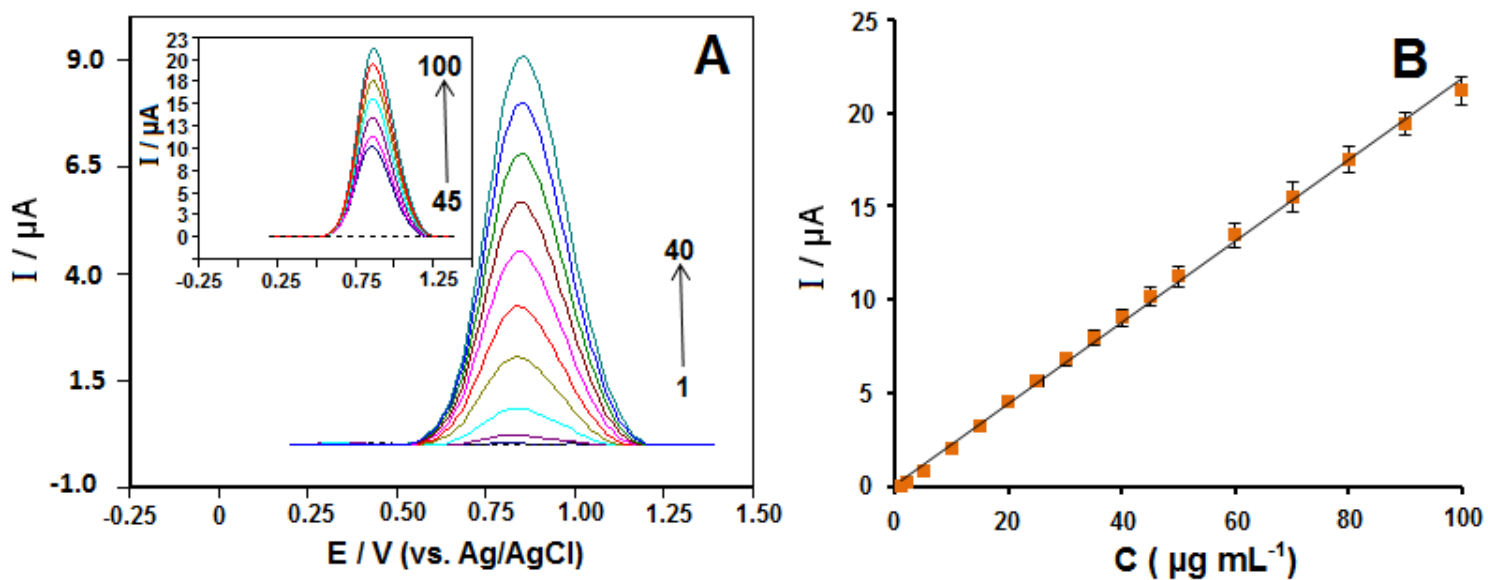

Fig. 5 - (A) SW-AdSVs obtained for NE at varying concentrations $\left(1 \mu \mathrm{g} \mathrm{mL}^{-1}-40 \mu \mathrm{g} \mathrm{mL}^{-1}\right)$ and (inset graph., $\left.45 \mu \mathrm{g} \mathrm{mL} L^{-1}-100 \mu \mathrm{g} \mathrm{mL}{ }^{-1}\right)$ at the OT-BDD electrode in $0.1 \mathrm{M} \mathrm{BR} \mathrm{pH} 2.0$ and related calibration graphic (B). $t_{a c c}$ period, $60 \mathrm{~s}$ at open circuit $E_{a c c}$, SWV conditions were $50 \mathrm{~Hz}$ frequency, $12 \mathrm{mV}$ scan increment and $70 \mathrm{mV}$ pulse amplitude.

Table 2

Comparison of the efficiency of the OT-BDD electrode with literature electrodes for NE determination

\begin{tabular}{|c|c|c|c|c|c|}
\hline Analyte & Electrode & $\begin{array}{c}\text { Linearity Range } \\
(\mu \mathrm{M})\end{array}$ & $\begin{array}{l}\text { LOD } \\
(\mu \mathrm{M})\end{array}$ & Sample & Ref. \\
\hline $\mathrm{NE}$ & $\mathrm{ME} / \mathrm{Au}$ SAMs & $2-100$ & 0.7 & Drug & 18 \\
\hline $\mathrm{NE}$ & $\mathrm{p}-\mathrm{ATD} / \mathrm{GCE}$ & $0.04-0.25$ & $1.7 \times 10^{-4}$ & Drug & 22 \\
\hline NE,AA, UA & PAAMWCNTs/SPCE & $1-10$ & 0.13 & - & 23 \\
\hline NE & Graphene/Pd & $0.5-500$ & 0.07 & Drug & 24 \\
\hline NE & $\mathrm{CACE} / \mathrm{GCE}$ & $0.55-9.7$ & 0.28 & Drug & 30 \\
\hline $\mathrm{NE}$ & $\mathrm{p}-\mathrm{TMP} / \mathrm{GCE}$ & $5-100$ & $8.0 \times 10^{-3}$ & Drug & 36 \\
\hline NE,DA & PL-Asp/GCE & $0.03-16$ & $4.31 \times 10^{-3}$ & Drug & 37 \\
\hline $\mathrm{NE}, \mathrm{AC}, \mathrm{FA}$ & MCM-CPE & $0.07-2000$ & 0.04 & $\begin{array}{c}\text { Synthetic } \\
\text { Mixture,urine }\end{array}$ & 38 \\
\hline $\mathrm{NE}, \mathrm{AC}, \mathrm{FA}$ & 5ADMBCNPEs & $15-1000$ & 8.0 & - & 35 \\
\hline $\mathrm{NE}$ & BDD & $4.9-490$ & 1.2 & Drug & This work \\
\hline
\end{tabular}

Analyte: NE, norepinephrine; AA, ascorbic acid; UA,uric acid; DA, dopamine: AC, acetaminophen ; FA, folic acid Electrode: $\mathrm{ME} / \mathrm{Au}$ SAMs, 2-Mercaptoethanol self-assembled monolayer; p-ATD/GCE, electropolymerized film of 2 amino-1,3,4-thiadiazole glassy carbon electrode; PAA-MWCNTs/SPCE, polyacrylic acid-multi-wall carbon nanotubes screen printed carbon electrode; Graphene/Pd, graphene palladium; p-TMP/GCE, 2,4,6-trimethylpyridine glassy carbon electrode; PL-Asp/GCE, poly L aspartic acid /glassy carbon electrode; CACE/GCE calix[4]arene crown-4 ether glassy carbon electrode; MCM-CPE nanostructured mesoporous materials, carbon paste electrode; 5ADMBCNPEs, 5-amino-3',4'-dimethoxy-biphenyl- 2-ol carbon nanotube paste electrode; BDD, boron-doped diamond.
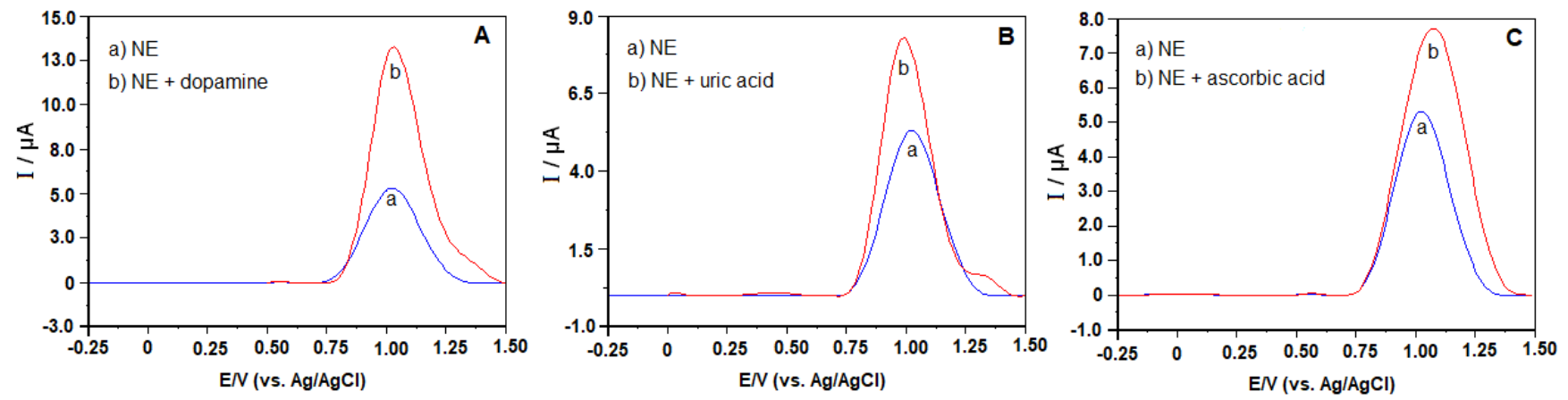

Fig. 6 - The stripping voltammograms showing the effect of interference of $10 \mu \mathrm{g} \mathrm{mL}^{-1}$ DOP (A), UA (B) and AA (C) on electrochemical signal of $10 \mu \mathrm{g} \mathrm{mL}^{-1} \mathrm{NE}$. Other operating conditions as indicated in Fig. 5. 
In this study, the sensitivity level obtained for $\mathrm{NE}$ analysis was compared with the sensitivity levels of other electroanalytical methods in the literature (Table 2). Our proposed method based on bare OT-BDD electrode has achieved a better sensitivity level than the study using 5ADMBCNPEs ${ }^{35}$ for oxidation of NE. However, modified electrode-based studies such as ${ }^{22,36}$ and ${ }^{37}$ have achieved significant sensitivity levels. Although modified electrodes improve analytical sensitivity, they do not have practical use due to disadvantages such as length of modification processes, low reproducibility and cost. The OTBDD electrode used in this study involve the potential to be an alternative in terms of having advantages such as a simpler, faster, not bad level of sensitivity and high reproducibility compared to modified electrodes for quantification of NE. Furthermore, the modification process that applied to improve the stability, selectivity, and sensitivity of the electrode surface may sometimes be useless in application to pharmaceutical formulations.

In the quantitative analysis of NE, the intra- and inter-day repeatability performance of OT-BDD electrode was investigated under the best experimental conditions. Its intra-day repeatability performance was examined by successively measuring the magnitude of the oxidation peak current signal at a concentration of $10 \mu \mathrm{g} \mathrm{mL}^{-1}$ $\left(4.9 \times 10^{-5} \mathrm{M}\right) \mathrm{NE}$. It was found to be repeatable with a relative standard deviation (RSD) value of $3.13 \%$ for twelve replicates. NE solution at the same concentration was measured with OT-BDD electrode for three consecutive days and the interday repeatability was determined to be $5.38 \%$ RSD. These results have indicated that the OTBDD electrode has achieved a high degree of precision, and reproducibility. Further, our effort was focused on application of proposed method for analysis of pharmaceutical drug forms.

Whether quantitative analysis of NE is possible in the presence of other common species can provide valuable information about the performance of the OT-BDD electrode. For this purpose, the effects of other common species on oxidation peak current were examined at $10 \mu \mathrm{g}$ $\mathrm{mL}^{-1}\left(4.9 \times 10^{-5} \mathrm{M}\right) \mathrm{NE}$ concentration. The tolerance limit was defined as the maximum concentration of matrix that caused an error $\pm 5 \%$ in the determination of NE. Selectivity studies were carried out by the addition of molecules such as ascorbic acid, uric acid, dopamine, sucrose, fructose, glucose and saccharin and metal ions such as $\mathrm{Ca}^{2+}, \mathrm{Mg}^{2+}, \mathrm{Fe}^{3+}, \mathrm{K}^{+}, \mathrm{Na}^{+}$, which have the potential to influence the analyte signal of interest and are commonly found in pharmaceutical sample and biological fluid contents. Interference effect was examined by adding three different matrix concentrations $(1: 1,: 1: 10,1: 100)$ to the related analyte. The results were evaulated by comparing the signals produced by the only NE-containing solution to those generated by NE solutions coexisting with the matrix. It was observed that saccharin, sucrose, glucose, fructose and other ionic species did not affect the oxidation peak signal of NE, even at a concentration of 100-fold. However, since the signals of ascorbic acid, dopamine and uric acid overlap with NE signals (Fig.6.), simultaneous analysis of these molecules with NE can only be performed by a separation ${ }^{39}$ or chemometric method. ${ }^{40}$

\section{Analysis of NE in pharmaceutical}

In order to investigate the accuracy of the proposed method and to test its practical applicability, the analysis of Stenor pharmaceutical dosages was performed by the SW-AdSV technique using the standard addition method (Figure 7). The preparation of the sample and the procedure applied to it are described in detail in section 2.3. The average results for six replicate measurements with acceptable standard deviations and relative confidence interval half-widths for $95 \%$ probability are summarized in Table 3. Good recovery values ranging from $95.87 \%$ to $104.7 \%$ prove that the method can be safely used on pharmaceuticals.

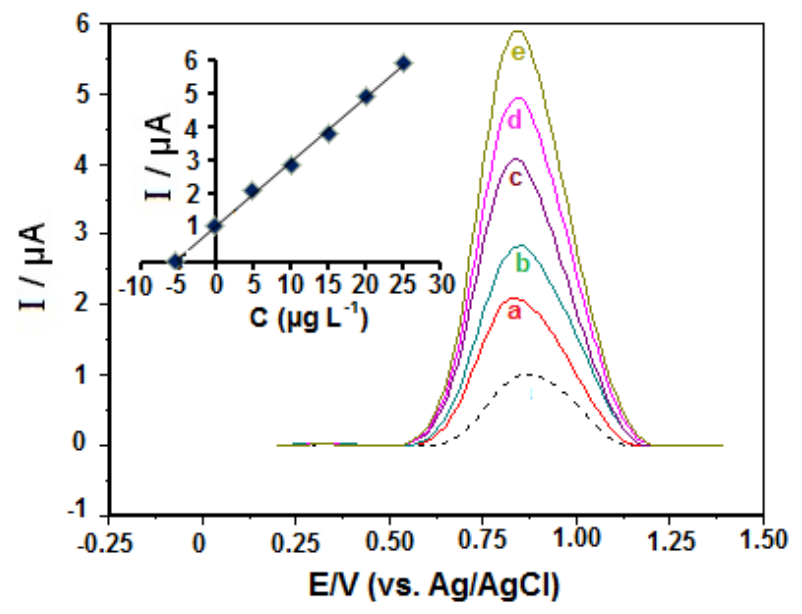

Fig. 7 - The SW-AdSV obtained for the determination of NE in pharmaceutical drug form. A 200 times diluted the sample (dashed line) and sample spiked at a NE levels of (a) $5 \mu \mathrm{g} \mathrm{mL}^{-1}$ (b) $10 \mu \mathrm{g} \mathrm{mL}^{-1}$, (c) $15 \mu \mathrm{g} \mathrm{mL}-1$ d) $20 \mu \mathrm{g} \mathrm{mL}^{-1}$ e) $25 \mu \mathrm{g} \mathrm{mL}^{-1}$.Other operating conditions as indicated in Fig. 5. 
Table 3

Measurement results of NE in Stenor ${ }^{\circledR}$ ampoule sample

\begin{tabular}{ccc}
\hline Added $\left(\boldsymbol{\mu} \mathbf{g} \mathbf{~ m L}^{-1}\right)$ & Found $\left(\boldsymbol{\mu} \mathbf{g ~} \mathbf{~ L}^{-\mathbf{1}}\right)$ & Recovery,$\%$ \\
\hline 0 & 5.47 & - \\
5 & 5.19 & 103.75 \\
10 & 10.47 & 104.70 \\
15 & 14.38 & 95.87 \\
20 & 19.46 & 97.30 \\
25 & 25.12 & 100.48 \\
\hline
\end{tabular}

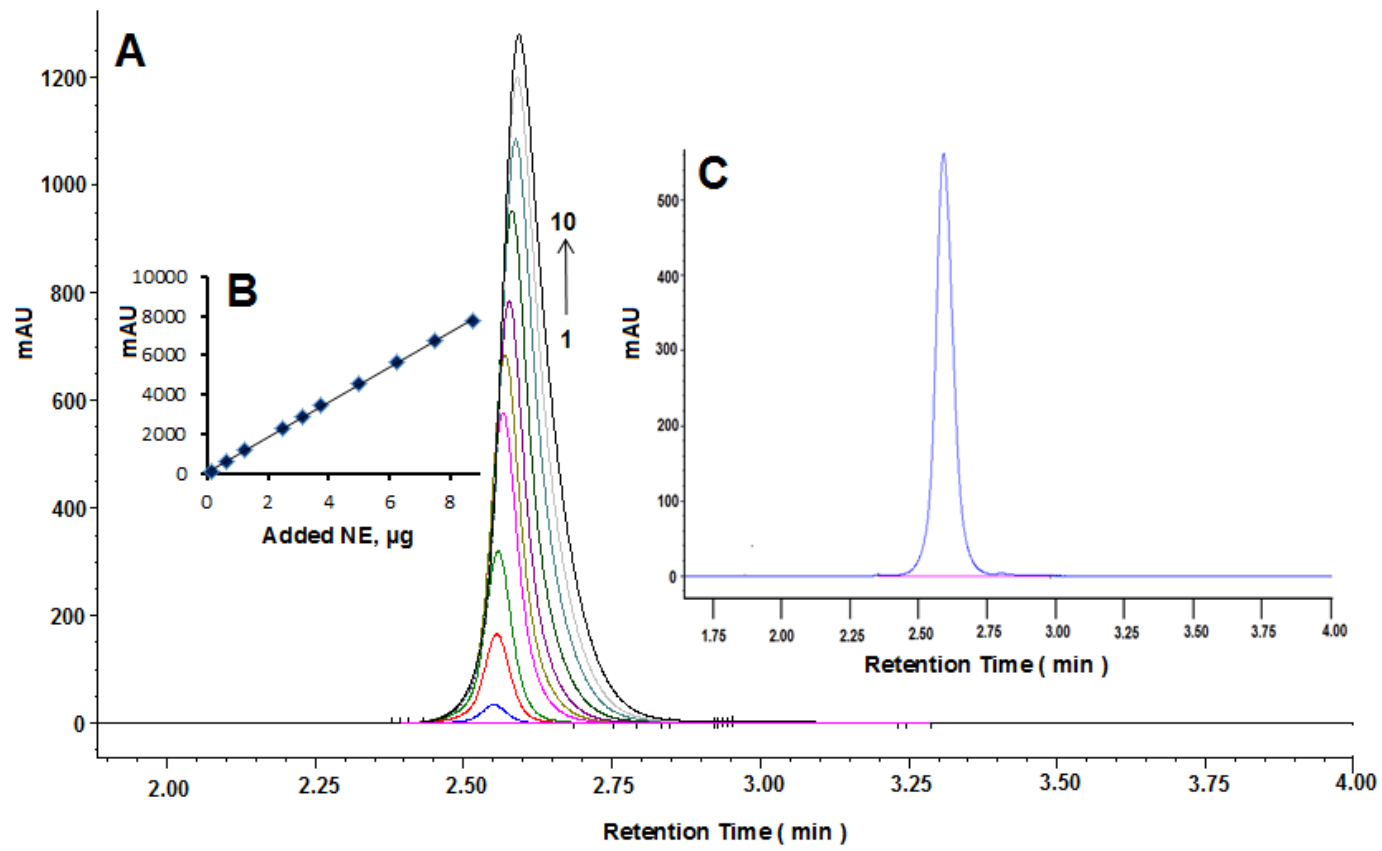

Fig. 8 - The standard solution chromatograms (A) and calibration plot of NE at different concentrations (B). The numbers 1-10 correspond to $0.125 \mu \mathrm{g}, 0.625 \mu \mathrm{g}, 1.25 \mu \mathrm{g}, 2.5 \mu \mathrm{g}, 3.125 \mu \mathrm{g}, 3.75 \mu \mathrm{g}, 5.0 \mu \mathrm{g}, 6.25 \mu \mathrm{g}, 7.5 \mu \mathrm{g}$ and $8.75 \mu \mathrm{g}$. Fig C: Typical chromatogram of NE in pharmaceutical drug form. Chromatographic conditions: mobile phase; methanol-water (70:30, v/v), flow rate; $1 \mathrm{ml} \mathrm{min}^{-1}$.

\section{Table 4}

Comparison of observed concentration of NE in pharmaceutical drug form at OT-BDD electrode by SWV and by using HPLC

\begin{tabular}{cccc}
\hline Labeled claim $\left(\boldsymbol{\mu g} \mathbf{~ m L}^{-1}\right)$ & $\mathbf{S W V}\left(\boldsymbol{\mu g} \mathbf{~ m L}^{-1}\right) \pm \mathbf{S D}$ & HPLC $\left.\boldsymbol{\mu} \mathbf{g} \mathbf{~ m L}^{-1}\right) \pm \mathbf{S D}$ & $\mathbf{E}^{\mathbf{a}}(\%)$ \\
\hline 1000 & $994.37 \pm 1.28$ & $996.14 \pm 1.96$ & -0.17 \\
\hline
\end{tabular}

${ }^{a}$ Relative error $(\%)=[($ Voltammetric Value - HPLC value $) /$ HPLC value $] x 100$

\section{Comparison by HPLC}

In order to prove the reliability of the analyses, the data obtained from the voltammetric analyses were compared with those obtained from the HPLC method. For this purpose, solutions of ten different concentrations of NE standards were prepared to cover the concentration in the drug sample and the concentrations against the observed peak areas were plotted (Fig.8). It was found that there was a highly linear relationship between $\mathrm{NE}$ concentrations and peak areas(Fig.8B) according to equation 10 :

$$
A=888.18 Q+63.011(r=0.9999)
$$

where A is peak area, Q is the amount of added NE $(\mu \mathrm{g})$ and $\mathrm{r}$ correlation coefficient. Figure $8 \mathrm{C}$ shows the characteristic HPLC chromotogram of NE in pharmaceutical drug at the retention time of $2.537 \mathrm{~min}$. The pharmaceutical drug content was 
determined from the HPLC chromatogram at 280 $\mathrm{nm}$ and expressed as microgram NE ( $\mu \mathrm{g} \mathrm{NE} / \mathrm{mL}$ ampoule) per milliliter of the drug. It was found that results of proposed method are not only comparable with labeled value on the pharmaceutical product but also with HPLC results (Table 3). The results obtained from both methods were statistically tested by applying paired $t$ test. Since the calculated $t$ value (2.55) is less than the critical $t$ value (2.78) in the $95 \%$ confidence interval, there is no difference between the precision of the two methods. These results indicate that there are no statiscally difference between the obtained results at the $95 \%$ confidence level.

\section{EXPERIMENTAL}

\section{Reagents and Solution}

Norepinephrine $\mathrm{HCl}$ was purchased from Sigma-Aldrich and used without any pre-purification. The standard stock solutions were prepared as $1000 \mu \mathrm{g} \mathrm{mL} \mathrm{m}^{-1}$ in water for voltammetric studies and $250 \mu \mathrm{g} \mathrm{mL}^{-1}$ in the mobile phase for chromatographic studies. When not in use, the solutions were stored in the dark at $4{ }^{\circ} \mathrm{C}$ in a refrigerator and protected from daylight during use. When necessary, stock solutions were used by diluting with the selected supporting electrolyte or mobile phase. A Britton-Robinson buffer was used as supporting electrolyte for voltammetric analyzes. The mobile phase was mixture methanol and water $\left(\mathrm{pH} 3.0\right.$ with $\mathrm{H}_{3} \mathrm{PO}_{4}$ in $85 \%(\mathrm{w} / \mathrm{w})$ purity) in the ratio of $70: 30(\mathrm{v}: \mathrm{v})$ for HPLC experiments. All solutions were filtered through $0.45-\mu \mathrm{m}$ pore-size filters(Agilent) using a vacuum system prior to use. Ultra-pure water produced by the Millipore-Q (Millipore) unit was used in the preparation of the aqueous solutions. All chemicals and solvents used throughout the study were of analytical and chromatographic grade and were used without any purification. Commercial drug formulation containing NE (Stenor $^{\circledR}$, Eczacibasi Ilac, Turkey) was purchased at a local pharmacy.

\section{Apparatus}

The electrochemical analysis was fulfilled with a $\mu$ Autolab type III potentiostat/galvanostat (Metrohm Autolab B.V., the Netherlands), which was managed by GPES 4.9 software. The raw signals of square wave voltammograms generated by the electrochemical instrument were recorded after the correction processing by moving average method $(0.03 \mathrm{~V}$ peak width) and the smoothing processing by Savicky and Golay algorithm in this software. All voltammetric experiments were conducted with three electrodes system in a glass electrochemical cell (volume of $10 \mathrm{~mL}$ ) maintained at ambient temperature. A platinum wire and an $\mathrm{Ag} / \mathrm{AgCl}(3 \mathrm{~mol}$ $\mathrm{L}^{-1} \mathrm{NaCl}$, Model RE-1, BAS, USA) were used as the counter and reference electrodes, respectively. The BDD electrode was obtained from Windsor Scientific Ltd. (UK). The BDD film electrode (boron content $1000 \mathrm{ppm}$ ), with poly-crystalline structure deposited on a polyether ether ketone tube with a $0.5 \mathrm{~mm}$ thickness and diameter of $3 \mathrm{~mm}$ declared by the provider was employed as working electrode. A pH meter model WTW inoLab720 equipped with a combined glass electrode was used to measure all $\mathrm{pH}$ values. Chromatographic analyses were performed using an Agilent 1100 series system coupled with a diode-array detector, an autosampler, and nucleosil column $(250 \mathrm{~mm} \times 4.6 \mathrm{~mm}, 5 \mu \mathrm{m})$. The mobile phase consisted of methanol and water $(70: 30, v / v)$ that was set at a flow rate of $1.0 \mathrm{ml} \mathrm{min}$.

\section{Measurement procedure}

Electrochemical analyzes were carried out in a $10 \mathrm{~mL}$ glass cell at room temperature $\left(20 \pm 5^{\circ} \mathrm{C}\right)$. At the beginning of each experimental day, the BDD electrode was subjected to an anodic pretreatment to improve its analytical performance and reproducible electrochemical activity after rinsing with water. For this, an anodic potential of $+1.5 \mathrm{~V}$ for $30 \mathrm{~s}$ was applied to the BDD electrode in order to form oxygen-terminated on its surface in $0.5 \mathrm{~mol} \mathrm{~L}^{-1} \mathrm{H}_{2} \mathrm{SO}_{4}$. Cyclic voltammetry (CV) method was firstly used in order to enlighten the electrochemical behavior of NE on bare BDD electrode for preliminary studies followed by SW-AdSV method for testing analytical performance and practicability of the method. The employed procedure for SW-AdSV analysis of NE was as follows: The formerly treated BDD electrode was immersed in a stirred (at $500 \mathrm{rpm}$ ) sample solution for $t_{a c c}$, at a chosen $E_{a c c}$ in order to accomplish NE pre-concentration. After a rest period of $10 \mathrm{~s}$, anodic scans were implemented in the range of +0.1 to $+1.3 \mathrm{~V}$ using the SW waveform to settle the solution and decrease the background current.

Prior to analytical applications, the best device signals were obtained at $50 \mathrm{~Hz}$ frequency, $70 \mathrm{mV}$ pulse amplitude, and $12 \mathrm{mV}$ scan increments values among SWV variables. Consecutive measurements were performed by applying the above procedure to the working electrode recursively. The calibration curve was obtained by adding the required amount of standard NE $\left(1000 \mu \mathrm{g} \mathrm{mL}^{-1}\right)$ stock solution to the electrochemical cell containing $10 \mathrm{~mL}$ of supporting electrolyte. Each value was analyzed with three replicates. LOD and LOQ were calculated as three and ten times the standard deviation of the the lowest concentration (in the linearity range) divided by the slope of the calibration curve, respectively.

\section{Pharmaceutical dosage form assay procedure}

Stenor $^{\mathbb{B}}$ ampoules (manufactured by Eczacibasi Ilac, Turkey) labeled to contain $4 \mathrm{mg} \mathrm{mL}^{-1} \mathrm{NE}$ per ampoule was used. Each $\mathrm{mL}$ of ampoule solution contain norepinephrine bitartrate equal to 1 $\mathrm{mg}$ norepinephrine base. One milliliter of this ampoule solution was transferred to a $10 \mathrm{~mL}$ volumetric flask and diluted to the mark with BR buffer solution ( $\mathrm{pH} 2.0$ ). Then, $0.5 \mathrm{~mL}$ of this solution was diluted to $10 \mathrm{~mL}$ with supporting electrolyte in the electrochemical cell. Further dilutions were made by sequential addition of standard solutions.

\section{Chromatographic conditions}

For comparison, a HPLC method was also used to determine $\mathrm{NE}$ in commercial pharmaceutical formulations. Standart solution of NE was prepared as $125 \mu \mathrm{g} \mathrm{mL}-1$ in mobile phase. The calibration curve was obtained by adding in the range of 1 to $70 \mu \mathrm{L}$ volume from $125 \mu \mathrm{g} \mathrm{mL}^{-1} \mathrm{NE}$ stock to the column and then measuring the peak area of the resulting chromatograms. The quantity measurements were calculated from the integration of the relevant peak areas. 


\section{CONCLUSIONS}

Modified electrodes whose chemically functionalized or morphologically altered by grafting are undoubtedly advantageous over bare electrodes in terms of selectivity and sensitivity. However, the advantage of bare electrodes lies in its ease of application, simplicity, and speed. This study demonstrates the applicability of the bare BDD electrode, state of art electrode material, as an electrochemical sensor in the determination of NE in pharmaceutical formulations without the need for any chemical modifications successfully. Furthermore, the NE concentration obtained in the commercial pharmaceutical formulation is statistically equal to that obtained using the HPLC method as the reference technique. Thus, the combination of SWV and an OT-BDD is a convenient and advantageous alternative for determining NE in the pharmaceutical formulation because it is very simple, inexpensive and fast. In addition, the advantageous aspect of the OT-BDD electrode allows it to be used safely in doping tests that require speed, simplicity and accuracy.

Acknowledgements. This work was financially supported by the Scientific Research Projects Presidency of Yüzüncü Y1l University ( Project Number : 2013-ECZ-B007).

\section{REFERENCES}

1. J. A. Ni, H. X. Ju, H. Y. Chen and D. Leech, Analyst, 1998, 123, 2895-2898.

2. Z. D. Peterson, D. C. Collins, C. R. Bowerbank, M. L. Lee and S. W. Graves, J. Chromatogr. B, 2002, 776, 221-229.

3. M. Taei and G. Ramazani, Colloids Surfaces $B$ Biointerfaces, 2014, 123, 23-32.

4. J. Futtrup, M. Nordentoft, B. Elfving and J. Krogh, Neurol. Psychiatry Brain Res., 2018, 30, 91-97.

5. P. D. Skosnik, R. T. Chatterton, T. Swisher and S. Park, Int. J. Psychophysiol., 2000, 36, 59-68.

6. R. Fujikawa, S. Higuchi, T. Ikedo, M. Nagata, K. Hayashi, T. Yang, T. Miyata, M. Yokode and M. Minami, Biochem. Biophys. Res. Commun., 2017, 486, 584-588.

7. J. Feng, C. Zhang, J. E. Lischinsky, M. Jing, J. Zhou, H. Wang, Y. Zhang, A. Dong, Z. Wu, H. Wu, W. Chen, P. Zhang, J. Zou, S. A. Hires, J. J. Zhu, G. Cui, D. Lin, J. Du and Y. Li, Neuron, 2019, 102, 1-17.

8. N. F. Atta, Y. M. Ahmed and A. Galal, J. Electroanal. Chem., 2018, 828, 11-23.

9. M. Mazloum-ardakani, H. Beitollahi and M. Kazem, Sensors Actuators B. Chem., 2010, 151, 243-249.

10. M. Mazloum-Ardakani, H. Beitollahi, M. A. SheikhMohseni, H. Naeimi and N. Taghavinia, Appl. Catal. A Gen., 2010, 378, 195-201.
11. V. Carrera, E. Sabater, E. Vilanova and M. A. Sogorb, 2007, 847, 88-94.

12. D. L. Kuhlenbeck, T. P. O’Neill, C. E. Mack, S. H. Hoke and K. R. Wehmeyer, J. Chromatogr. B. Biomed. Sci. Appl., 2000, 738, 319-30.

13. H. W. Wu, M. L. Chen, D. Shou and Y. Zhu, Chinese Chem. Lett., 2012, 23, 839-842.

14. M. Zhu, X. Huang, J. Li and H. Shen, Anal. Chim. Acta, 1997, 357, 261-267.

15. F. Ghasemi, M. R. Hormozi-Nezhad and M. Mahmoudi, Anal. Chim. Acta, 2016, 917, 85-92.

16. E. Asadian, M. Ghalkhani and S. Shahrokhian, Sensors Actuators, B Chem., 2019, 293, 183-209.

17. R. N. Goyal, A. Aziz, M. Oyama, S. Chatterjee, A. Raj and S. Rana, Sensors Actuators B. Chem., 2011, 153, 232-238.

18. X. Zhang and S. Wang, Sensors, 2003, 3, 61-68.

19. N. F. Atta, M. F. El-kady and A. Galal, Anal. Biochem., 2010, 400, 78-88.

20. Y. Li, Y. Umasankar and S. Chen, Anal. Biochem., 2009, 388, 288-295.

21. R. N. Goyal and S. Bishnoi, Talanta, 2011, 84, 78-83.

22. P. Kalimuthu and S. Abraham John, Electrochim. Acta, 2011, 56, 2428-2432.

23. S. Huang, H. Liao and D. Chen, Biosens. Bioelectron., 2010, 25, 2351-2355.

24. Rosy, S. K. Yadav, B. Agrawal, M. Oyama and R. N. Goyal, Electrochim. Acta, 2014, 125, 622-629.

25. M. Amiri-Aref, J. B. Raoof and R. Ojani, Sensors Actuators, B Chem., 2014, 192, 634-641.

26. X. Ma, Z. Wang, X. Wang and L. Xu, J. Solid State Electrochem., 2012, 17, 661-665.

27. R. N. Goyal, M. A. Aziz, M. Oyama, S. Chatterjee and A. R. S. Rana, Sensors Actuators, B Chem., 2011, 153, 232238

28. L. Švorc, K. Borovská, K. Cinková, D. M. Stanković and A. Planková, Electrochim. Acta, 2017, 251, 621-630.

29. F. Dönmez, Y. Yardım and Z. Şentürk, Diam. Relat. Mater., 2018, 84, 95-102.

30. H. Zhang, Y. Liu, G. Lai, A. Yu, Y. Huang and C. Jin, Analyst, 2009, 134, 2141-2146.

31. A. J. Bard and L. R. Faulkner, Electrochemical Methods: Fundamentals and Applications, John Wiley \& Sons, New York, 2nd edn., 2001.

32. E. Laviron, J. Electroanal. Chem., 1979, 101, 19-28.

33. E. R. Sartori, D. N. Clausen, I. M. R. Pires and C. A. R. Salamanca-Neto, Diam. Relat. Mater., 2017, 77, 153158.

34. Y. Yardim and Z. Şentürk, Turkish J. Pharm. Sci., 2014, $11,87-100$.

35. H. Beitollahi, A. Mohadesi, K. S. Mahani, H. KarimiMaleh and A. Akbari, Ionics (Kiel)., 2012, 18, 703-710.

36. H. Zhao, Y. Zhang and Z. Yuan, Electroanalysis, 2002, $14,445-448$

37. Z. Yu, X. Li, X. Wang, X. I. A. Li and K. Cao, J. Chem. Sci., 2012, 124, 537-544.

38. M. Mazloum-Ardakani, S. M. Mohammad, M. Abdollahi-Alibeik and A. Benvidi, Sensors Actuators B. Chem., 2012, 171-172, 380-386.

39. A. Yiğit, Y. Yardim and Z. Şentürk, IEEE Sens. J., 2016, $16,1674-1680$.

40. M. Esteban, C. Ariño and J. M. Díaz-Cruz, Crit. Rev. Anal. Chem., 2006, 36, 295-313. 